\title{
THE EXPERIMENTAL CONTUSION INJURY OF THE SPINAL CORD IN SHEEP
}

\author{
By J. D. Yeo ${ }^{1}$, W. PaYnE ${ }^{2}$, B. Hinwood ${ }^{3}$ \\ Kolling Institute of Medical Research, Royal North Shore Hospital of Sydney \\ and \\ A. D. Kidman ${ }^{4}$ \\ School of Life Sciences, New South Wales Institute of Technology, St. Leonards
}

\section{INTRODUCTION}

A HIGH percentage of patients with spinal cord damage suffer permanent paralysis and loss of sensation below the level of the spinal cord injury. Since 1956, 550 patients have received treatment in the Spinal Injuries Unit at the Royal North Shore Hospital of Sydney. In many cases the spinal cord was severely bruised rather than lacerated by displacement of the vertebral column. Autopsies confirmed that, although apparently intact, the contused neurones cease to function. In these patients, medical reassessment confirmed that the lesion was irreversible from the moment of injury. Recent experimental work has supported the concept that this apparently irreversible spinal cord injury in man could be reversed partially by physical or chemical means (Albin et al., I968; Ducker and Hamit, 1969; Kelly et al., I970; Osterholm and Mathews, 1972).

Whatever future treatment arises from the present research programmes, the clinician will have to solve the problem of differentiating concussion, contusion and laceration in the recently 'shocked' spinal cord.

\section{AIMS}

The need for further clarification of the pathology following moderately severe contusion injury to the spinal cord stimulated the authors to design a suitable experimental model using sheep.

The following aspects of the controlled contusion injury in the thoracic spinal cord of sheep (Tro level) were investigated:

I. The validity of the 'reproducible' contusion injury in the experimental animal (adult female sheep).

2. The sequential pathological changes in the moderately contused spinal cord of the sheep (Tro spinal level).

3. The use of isotope myelography to define the degree of spinal cord damage which follows moderate contusion injury.

${ }^{1}$ Spinal Injuries Unit, Royal North Shore Hospital of Sydney.

${ }^{2}$ Clinical Pathology, Royal North Shore Hospital of Sydney.

${ }^{3}$ Royal North Shore Hospital of Sydney.

${ }^{4}$ Neurobiology Unit, School of Life Sciences, New South Wales Institute of Technology. 


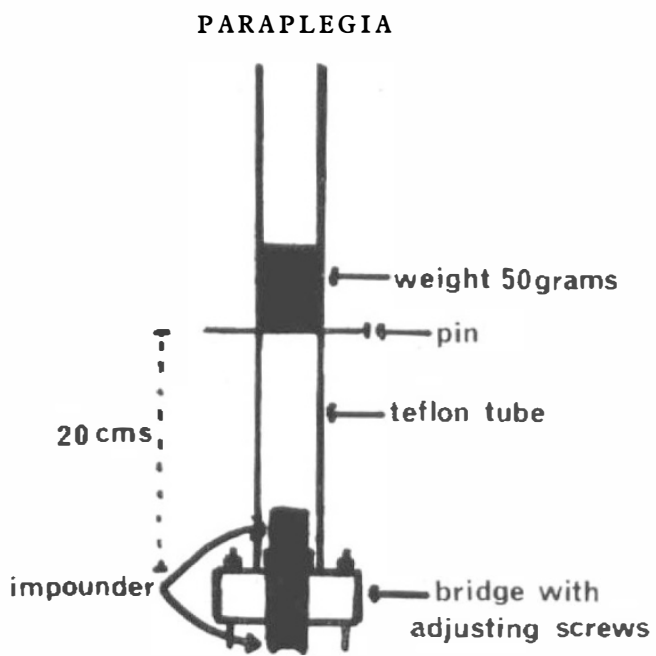

FIG. I

Diagram showing a weight of $50 \mathrm{~g}$ placed in the vertical Teflon tubing which is positioned on an adjustable bridge astriding the spinal cord. The falling weight will produce an impact transmitted by the impounder to the underlying spinal cord.

4. The pattern of sensory and motor recovery in a group of control animals (sheep) compared with separate groups, which had received the following treatment:

(i) intrathecal methyl prednisolone (Depo-Medrol $40 \mathrm{mg}$.) within 60 minutes of injury.

(ii) intravenous alpha-methyl paratyrosine (I00-I60 mg./kg.) within 75 minutes of injury.

5. The chronic pathology found in the lower thoracic spinal cord of sheep following a controlled contusion injury-a study over I to I7 weeks.

\section{METHODS AND TECHNIQUES}

The reproducible 'moderate' contusion injury resulted when $50 \mathrm{gm}$. was dropped in a Teflon tube from a height of $20 \mathrm{~cm}$. on to an impounder positioned over the exposed spinal cord of the adult female sheep (TIO level). Figure I shows that the dura was removed. The surface area of the impounder in contact with the cord was $50 \mathrm{sq}$. mm. The injury resulted in a profound paraplegia and sensory loss in the hind limbs (figs. 2 and 3) (M. S. Albin, R. J. White, G. AcostaRua and D. Yashon, I968; Yeo, Collins and Payne, I97I).

\section{The Contusion Injury}

(a) The macroscopic appearance of each spinal cord was recorded, and isotope and contrast myelography used to monitor the degree of spinal cord swelling.

(b) An electrical stimulus (2-5 volts for 0.05-0.I msec.) was applied to the dorsal surface of the spinal cord $\mathrm{I} \mathrm{cm}$. above and below as well as at the level of the injury and the motor response noted before and after injury.

(c) The histopathology was compared in I I animals at 30 minutes, 40 minutes and 120 minutes after injury. 

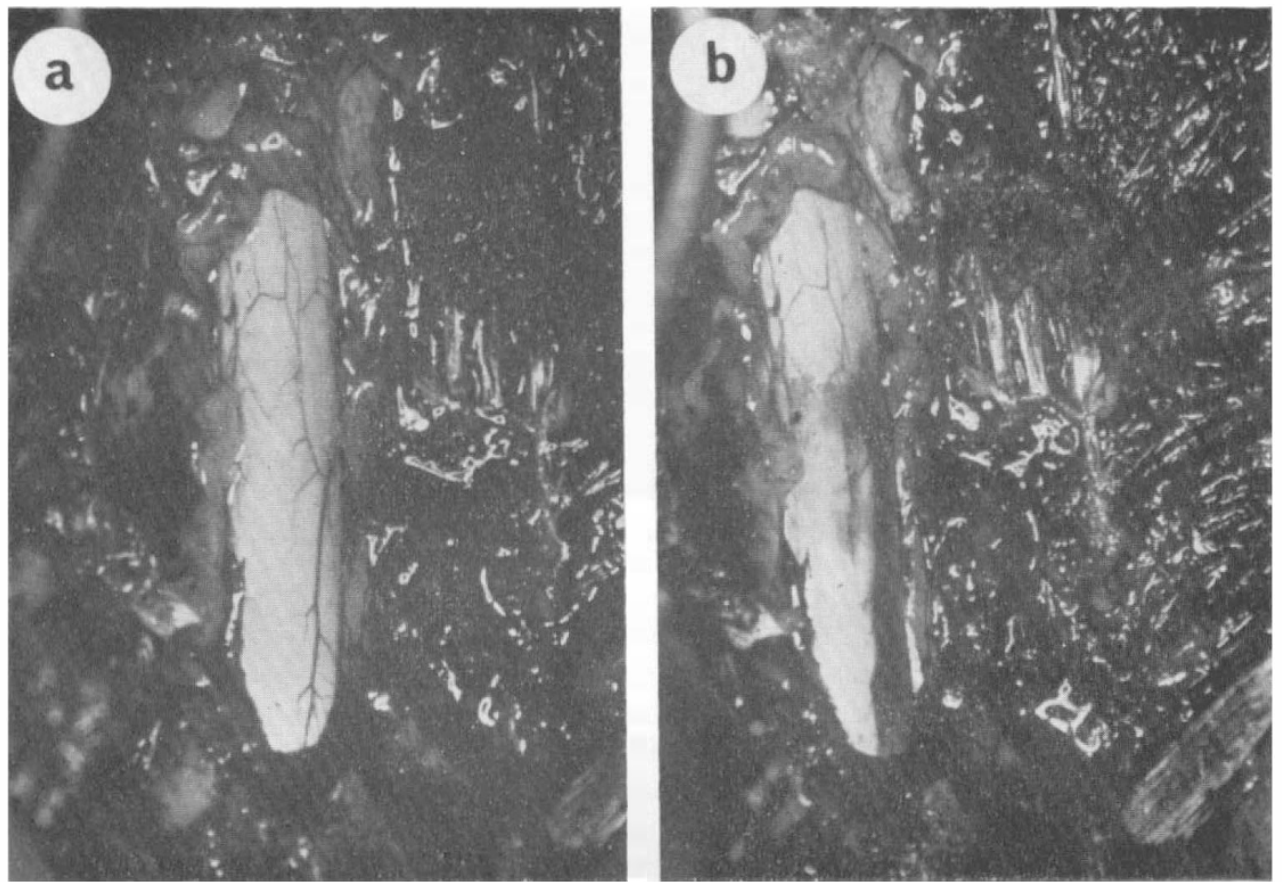

FIG. 2 (A)

Normal appearance of the posterior surface of the exposed lower thoracic spinal cord, (dura removed).

FIG. 2 (B)

Appearance following a contusion injury from a weight of $50 \mathrm{~g}$ dropped from a height of $20 \mathrm{~cm}$. on to the posterior surface of the spinal cord at Tio level.

\section{Sequential Pathology}

(a) The early pathological changes in the contused spinal cord were studied from Io minutes to two days after injury.

(b) In 12 animals, ideal fixation of tissue for light microscopy was obtained by perfusion fixation.

(c) Sections of the spinal cord were stained with haematoxylin/eosin and Luxol fast blue.

\section{Isotope Myelography}

(a) Isotope myelography was used to study the degree of spinal cord swelling which occurred within two hours of the injury. The following isotopes were injected intrathecally at the $\mathrm{L}_{7} / \mathrm{S}_{\mathrm{I}}$ intervertebral space within one hour of injuryIsotope $\mathrm{I}^{131}$ labelled radio-iodinated human serum albumin (R.I.S.A.), Technetium 99m human serum albumin (H.S.A.) and Ytterbium I69 Diethylene Triamine Penta-Acetic Acid (D.T.P.A.).

(b) Contrast myelography was also performed and the findings compared with isotope myelography. 


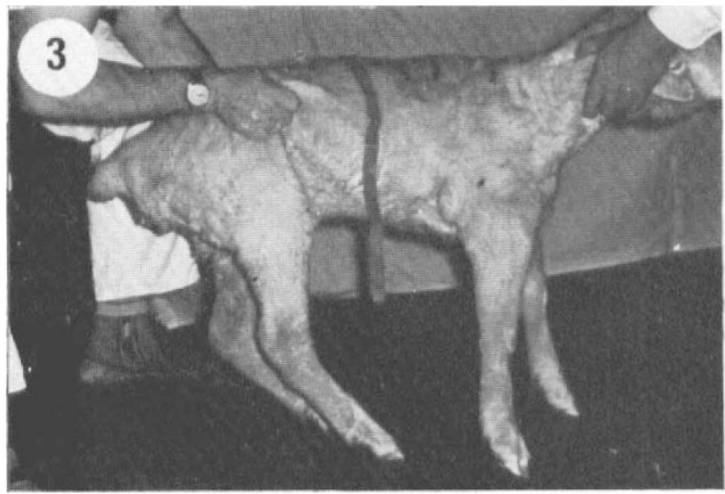

FIG. 3 Complete sensory loss and paraplegia below TIO spinal level, following the contusion injury.

FIg. 4 The paraplegic sheep nursed in a supportive sling.

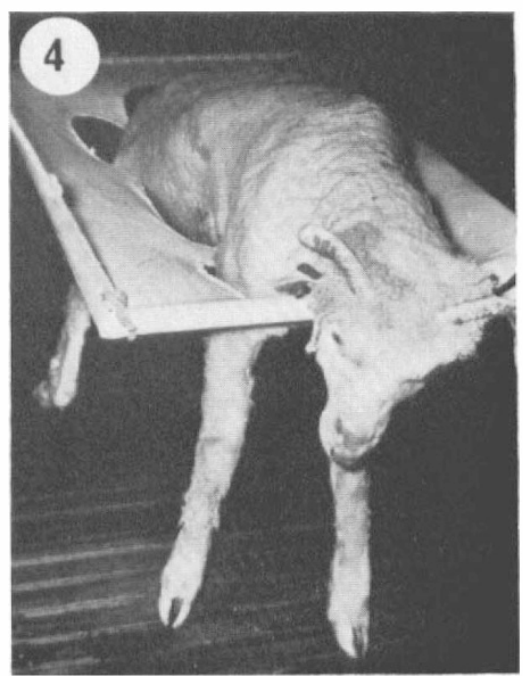

(c) The degree of spinal fluid block was defined as: (i) nil, (ii) partial, (iii) complete.

\section{Clinical Assessment}

(a) Control Series. In a long-term clinical study over three months, each animal was nursed in a supportive sling and lifted at regular intervals to avoid trophic skin ulceration (fig. 4). When necessary, adequate fluid balance was maintained using intravenous therapy during the first 48 hours. Early return of reflex micturition usually eliminated the necessity for an indwelling catheter. The clinical examination comprised: (i) assessment of the extensor and flexor movements above the stifle joint ('knee' joint), (ii) examination of the flexor and extensor movements below the stifle joint, (iii) assessment of the degree of 'hoof drop' in both lower limbs, (iv) the assessment of the response to painful stimuli above and below the stifle joints in both limbs. A sheep with normal function and sensation would have a total rating of 24 for both hind limbs. A group of I 5 animals studied for periods up to 13 weeks, served as the initial control series.

In two sheep a tape, $I \mathrm{~cm}$. in width, was tied around the spinal cord at TIo level for 48 hours, producing a complete block and presumably serious ischemia over this period. After removal of the tape, the animal's clinical recovery was studied for six weeks.

(b) Treated Series. (i) The recovery in I I sheep, which had received $40 \mathrm{mg}$. methyl prednisolone (Depo-Medrol) intrathecally within one hour of the injury was studied for periods up to I 3 weeks. (ii) Recovery in four animals, which had received alpha-methyl paratyrosine (I00 $\mathrm{mg} . / \mathrm{kg}$.) intravenously within I hour $\mathrm{I} 5$ minutes of the injury, was studied. Recovery in this treated group of animals was compared to the recovery seen in a control group of five animals who were given only intravenous infusion of saline $(25 \mathrm{ml} . / \mathrm{kg}$.) commencing 15 minutes after injury and completed within one hour. All animals were examined four hours after injury, 24 hours later and then at least three times weekly for the period of 
the study. The clinical examiner was not aware of the group into which the animal belonged.

\section{Chronic Pathology}

Autopsies were carried out in all animals in both treated and untreated groups when possible. The macroscopic appearance of the spinal cord, up to three months after injury, was photographed. Sections were taken at the level of the injury, I cm. above and I cm. below and in each section the changes in grey matter and posterior, lateral and anterior columns of white matter were studied. Central cystic necrosis was demonstrated by dark field illumination. The progressive cystic changes within the central area of the spinal cord tissue were studied from periods of five days to 17 weeks.

\section{RESULTS}

Variations in the Controlled Contusion Injury. The degree of contusion occurring within I20 minutes varied considerably even though the impact injury was standardised at Tro level. Macroscopic, as well as microscopic, differences in the degree of congestion, extravasation and axonal swelling were evident in white and grey matter. In order to assess the amount of variation, four spinal cords were studied at 30 minutes after injury, four spinal cords were studied at 40 minutes after injury and three spinal cords were studied at 120 minutes after injury.

Spinal cords of four untreated animals were compared 13 weeks after injury and marked cystic changes were evident. Only a rim of white matter was spared on the periphery of the shrunken cord. Some variation in the glial response with central cystic degeneration was seen (fig. 5).

There was a varied response in the crushed nerve tissue to external stimulus ( 5 volts over $0.05 \mathrm{msec}$. duration at a frequency of I per sec.). In 55 animals, the stimulation was applied over three segments of the exposed cord on both right and left sides (dura removed). The muscular response to the stimulus was observed and compared to the response after injury. In almost all animals, the response to the stimulus above the lesion remained similar to the response before injury. In 39 sheep (7I per cent), there was complete absence or only slight evidence of muscular response to the external stimulus at the level of the lesion. This variation in response to an external stimulus by the nerve cells and fibres was interpreted as a variation in the degree of immediate injury to the underlying nerve tissue. Clinical recovery of motor power varied within four hours (0-58 per cent of normal).

The results of contrast myelography in four animals with contused spinal cords have been summarised (fig. 6). The time intervals in the Pantopaque study are shown in the right-hand column. Each animal is identified by a number on the right of the diagram and the two parallel lines represent the extent of the flow. The cord swelling varies as shown by the results of contrast myelography in four animals. One animal showed an incomplete block at one hour, while 'complete' blocks were present in three other animals.

Sequential Changes in the Early Pathology. The sequential pathological changes in the moderately contused spinal cord showed a dynamic pattern in both 

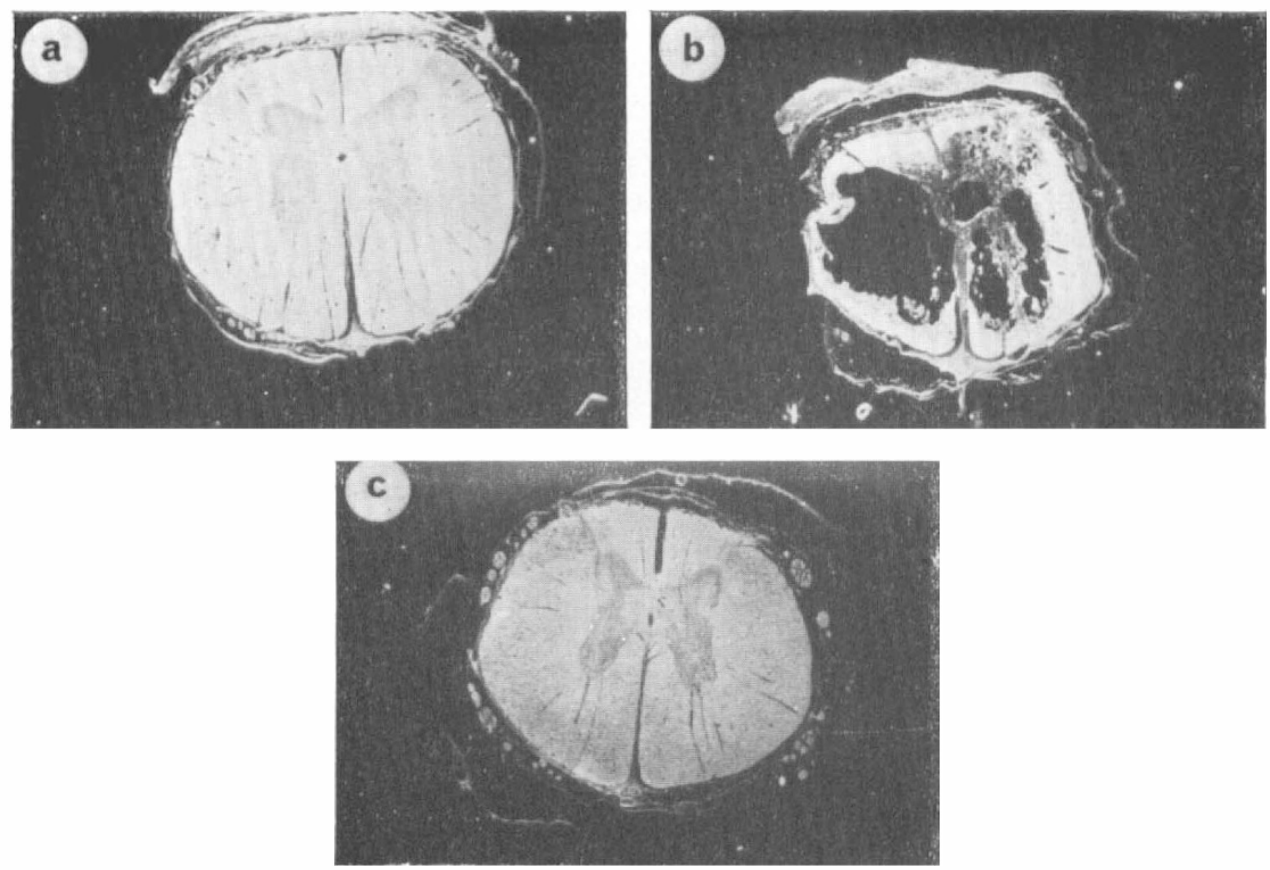

FIG. 5

I2 weeks after injury-cross-sections of the sheep's spinal cord at I $\mathrm{cm}$. intervals above and below Tio level (dark field illumination). Marked central cystic changes are localised to the Tro level. Microcysts are evident in the white matter I cm. above and below the lesion.

grey and white matter within the first two days of injury. In the series of I4 animals subjected to controlled contusion, the spinal cords were examined at periods from ten minutes up to two days after injury. The lesion appeared remarkably localised. There was restricted extension of congestion, haemorrhage and nerve fibre damage above and below the lesion level over a distance of $2 \mathrm{cms}$.

At the level of the lesion, congestion of the small vessels in the grey matter and, to a lesser extent, in the white matter was evident within 15 minutes. These changes progressed in both grey and white matter over two hours. At 15 minutes, slight swelling of some axons within intact myelin sheaths was also seen. Oedema was only evident where fixation perfusion had been used. Perfusion in these animals was carried out at intravascular pressures approaching $160 \mathrm{~mm}$. $\mathrm{Hg}$. The range of normal systolic blood pressures in the adult female sheep under general anaesthesia had been found to be in the range of I00-I $20 \mathrm{~mm}$. $\mathrm{Hg}$ (figs .7 $\mathrm{A}-\mathrm{H})$.

By four hours there was evidence of marked axonal swelling with some myelin cylinders apparently without a central axon. There was a very striking change seen between four hours and two days post-injury. The spinal cord, two days after injury, had extensive haemorrhage in both grey and white matter with extravasation and generalised breakdown in the normal structure of the myelin sheath. Many myelin sheaths, in cross-section, had no axons. Those axons which remained 


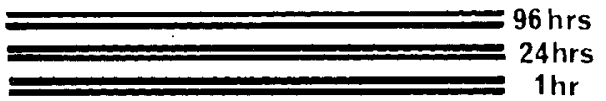

43

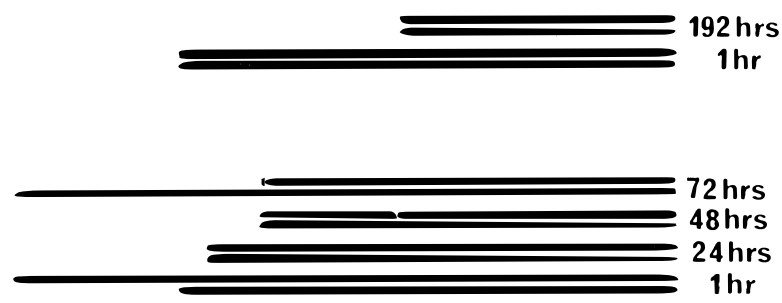

46

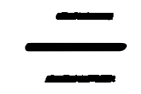

96 hrs

49

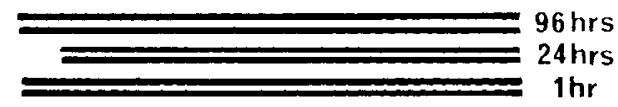

Ven. Cer. U.Th. CRU. L.Th. Lum. Inj.

FIG. 6

Diagrammatic summary of contrast myelography used in four animals, to study the degree and duration of post traumatic spinal cord swelling. The time intervals after injury are indicated for each animal on the right-hand side of the diagram. The flow of the contrast medium in the subarachnoid space is represented by the heavy horizontal lines. No. 42, 'complete block persisted for 96 hours after injury'; No. 43, 'complete block persisted for I92 hours after injury'; No. 46, 'incomplete block at I hour after injury-remaining incomplete for at least 72 hours'; No. 49, 'complete block at 24 hours-incomplete at 96 hours'.

were swollen and displaced from their central position within the myelin sheaths. All sections illustrated are from the anterior columns of white matter adjacent to the anterior grey horn, to allow comparison of sequential pathological changes (magnification $-\times \mathrm{I} 28$ ). The small microcysts in the white matter, evident at two and four hours, appeared to result from the coalescence of the adjacent, disrupted myelin sheaths. There was therefore evidence of irreversible damage at four hours after injury. It would be of interest to examine the crushed spinal cord tissue between four hours and 48 hours in more detail. The absence of significant, extracellular oedema fluid has been emphasised by other workers (Vise, Yashon and Hunt, 1974) and suggests a variation in the cellular and humoral response to tissue damage in the spinal central nervous system.

Assessment of Cord Swelling by Isotope Myelography. In experiment 50, a complete block to spinal fluid flow was confirmed up to 24 hours after injury by both isotope and contrast myelography. Isotope myelography was repeated at 44 hours and showed an incomplete block. Contrast myelography at 48 hours and 96 hours still indicated an apparent 'complete block'. Only at I 20 hours did the contrast medium flow cephalward around the swollen segment of spinal cord. 

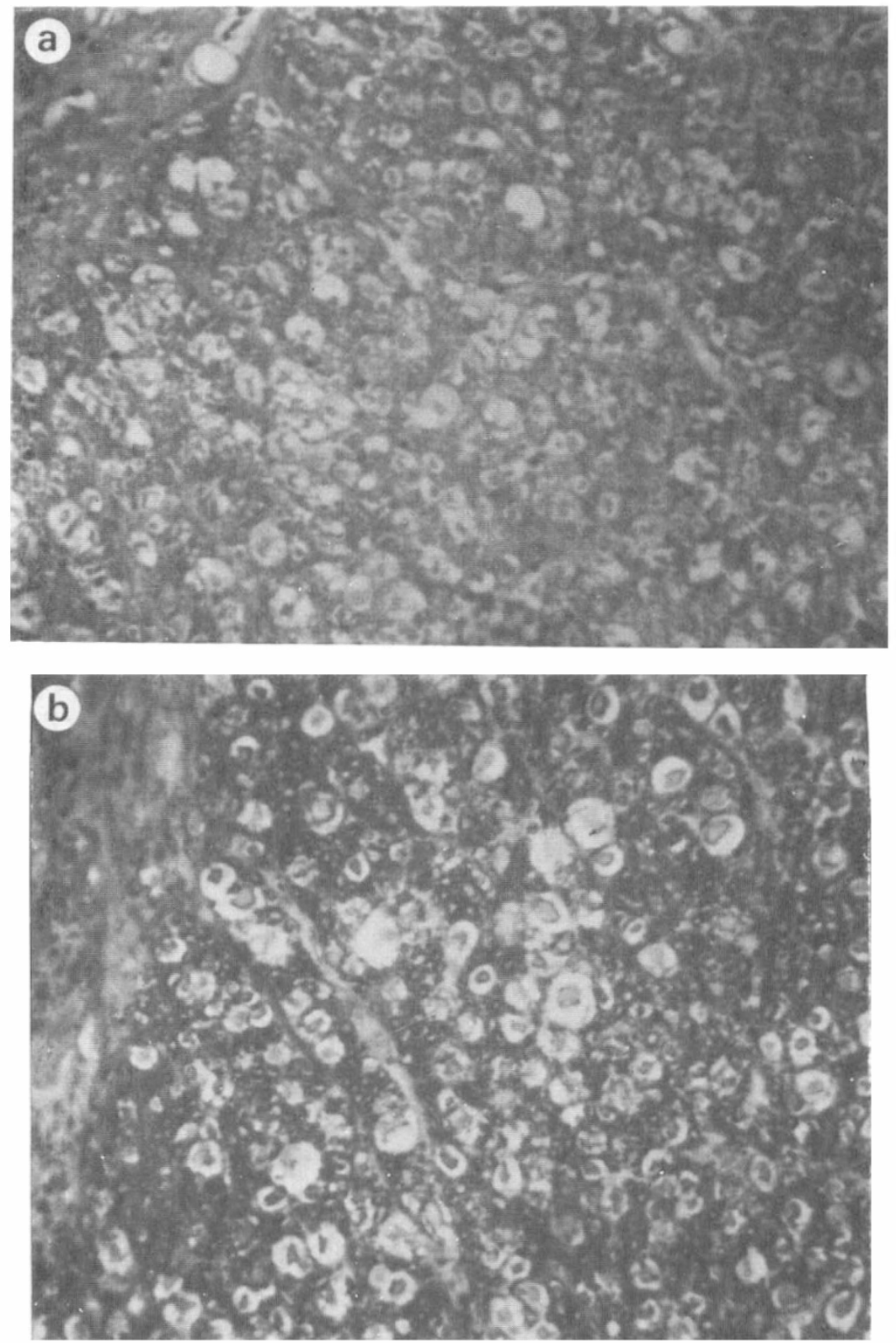

FIG. 7 (A and B)

Histology: anterior column of white matter. Stain-Luxol fast blue. Magnification $\times 128$. (A) Normal. (B) I 5 minutes after injury-mild swelling of axons. 

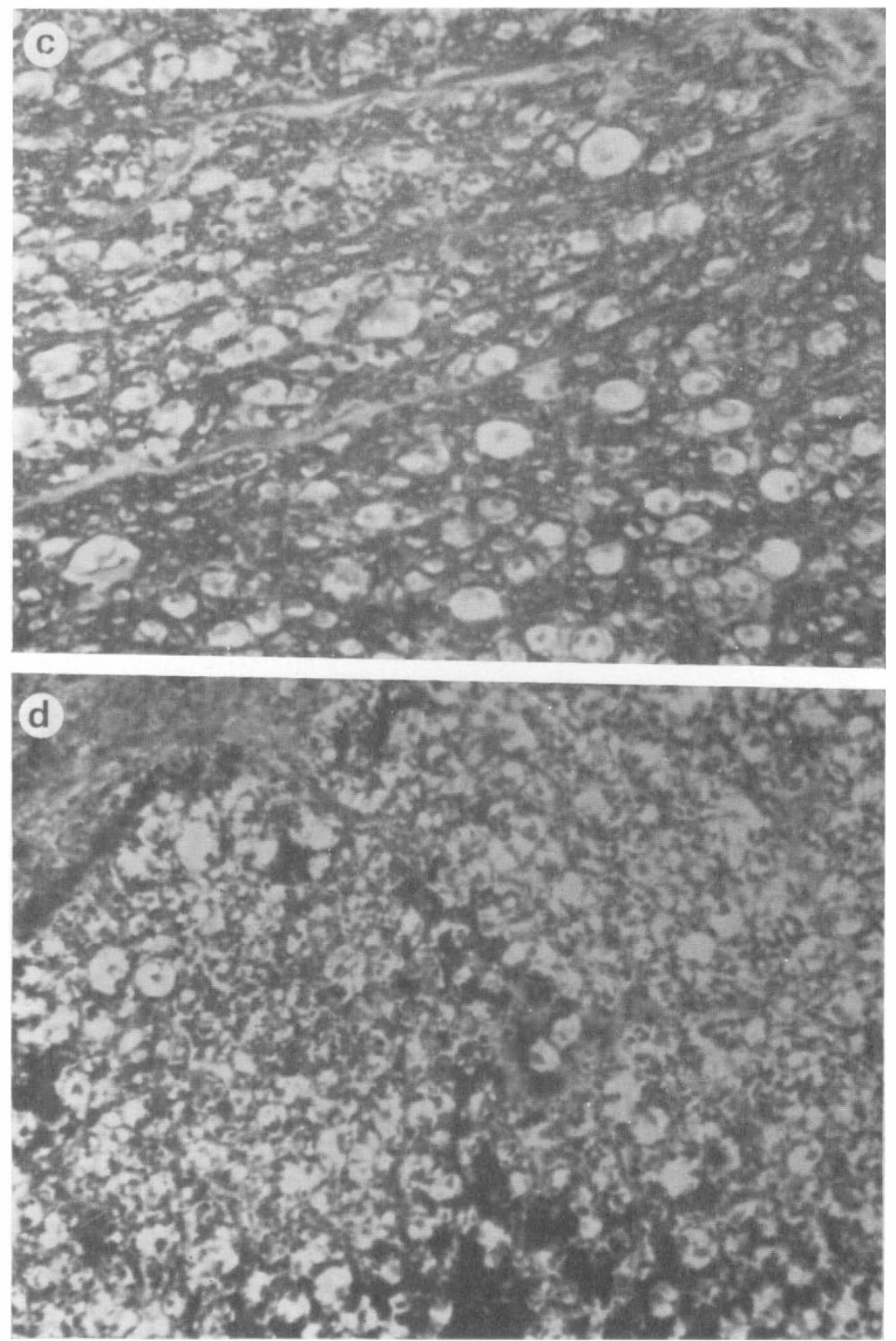

FIG. 7 (C and D)

Magnification $\times$ I28. (C) At 30 minutes-swelling axons and periaxonal spaces, mild congestion. (D) At 40 minutes-increased congestion and extravasation of red blood cells; some disruption of myelin sheaths is now evident.

I2/4-T 

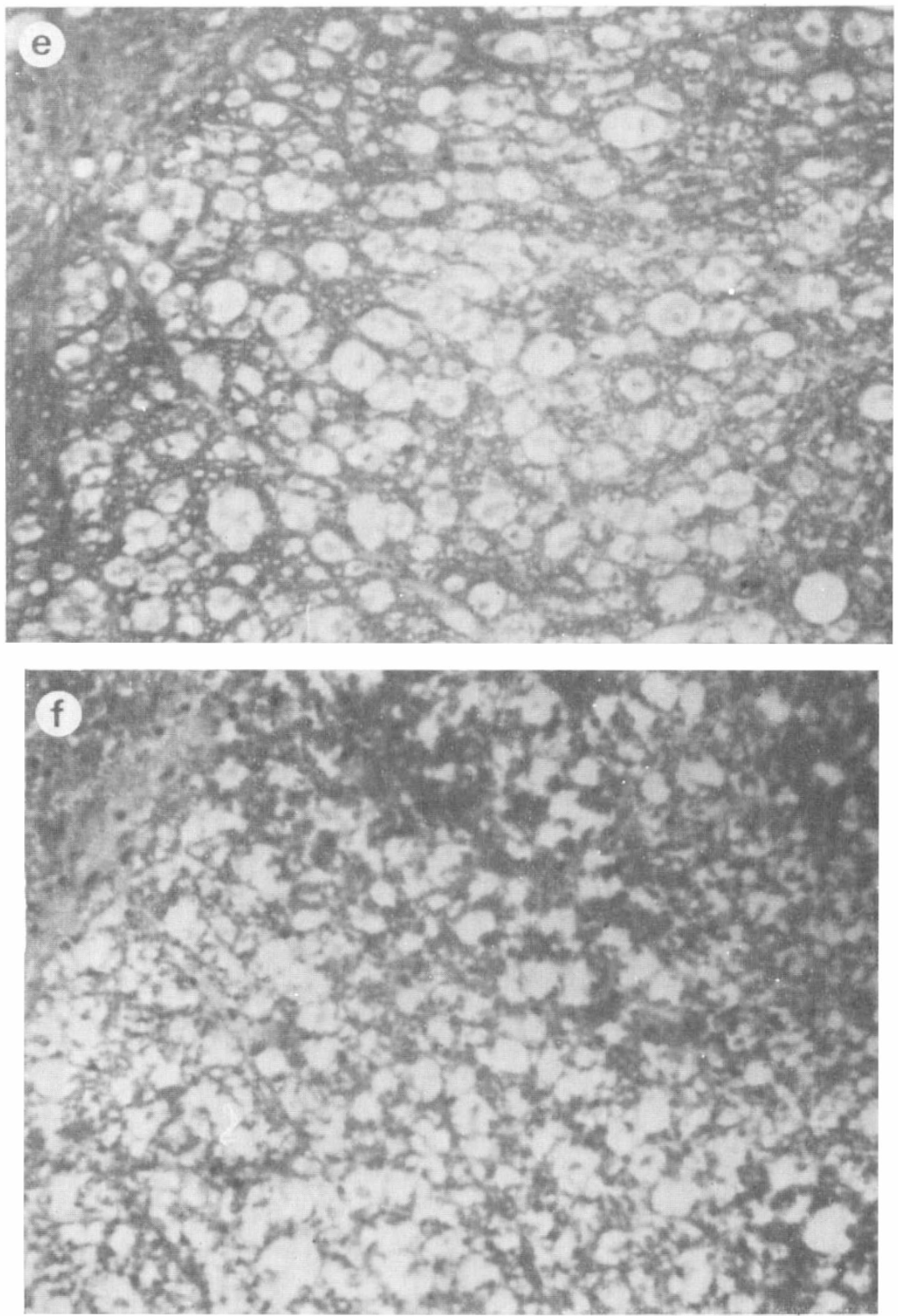

FIG. 7 (E and F)

Magnification $\times$ I28. (E) At 65 minutes-some myelin sheaths now no longer have a demonstrable axon. (F) At 120 minutes-extensive loss of axons, disruption of myelin sheaths; progressive extravasation of red blood cells. 

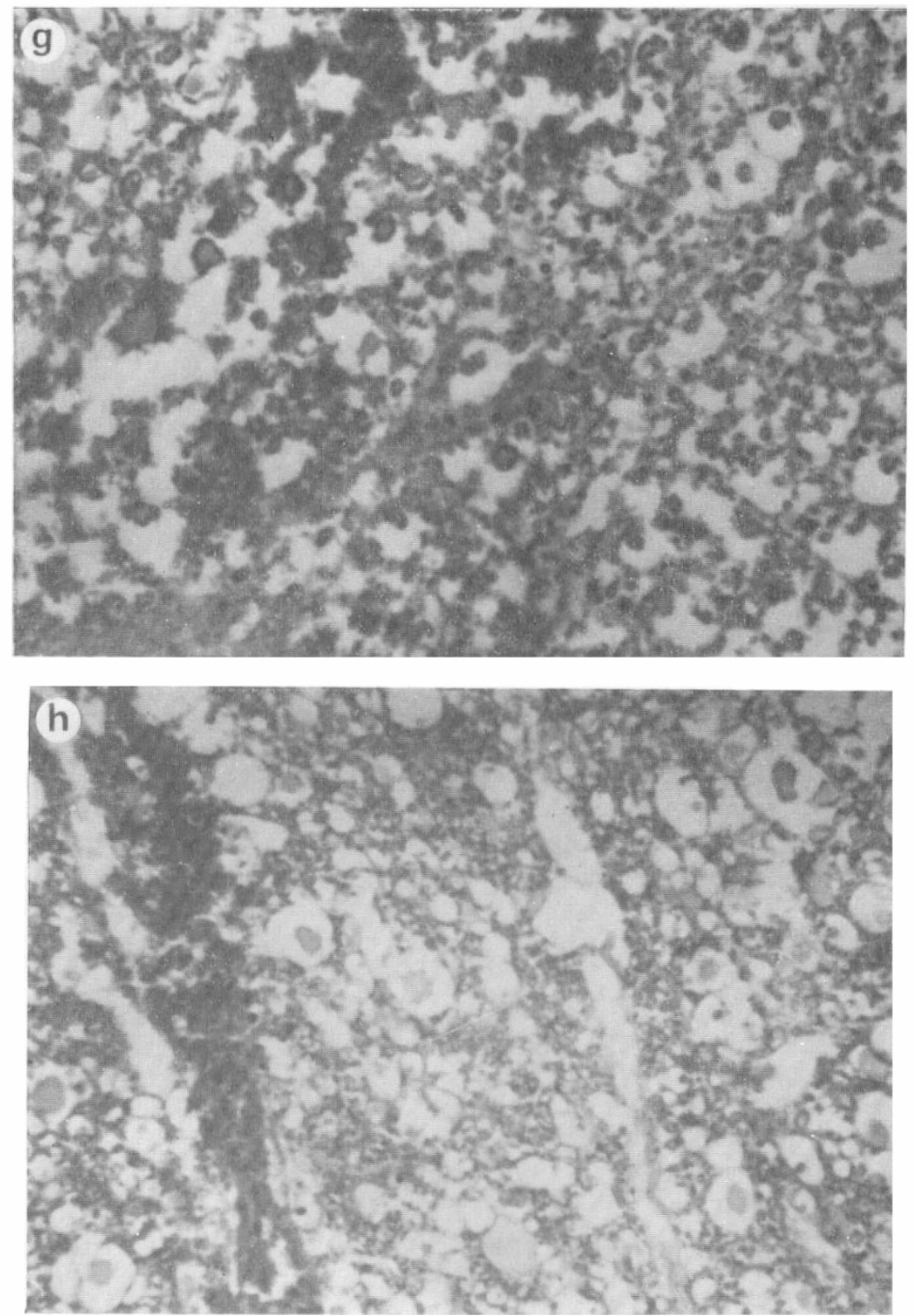

FIG. 7 (G and $\mathrm{H}$ )

Magnification $\times$ I28. (G) and $(\mathrm{H})$ At two days and five days after injury-marked swelling of axons and disruption of myelin sheaths. Extravasation of red blood cells is widespread. 


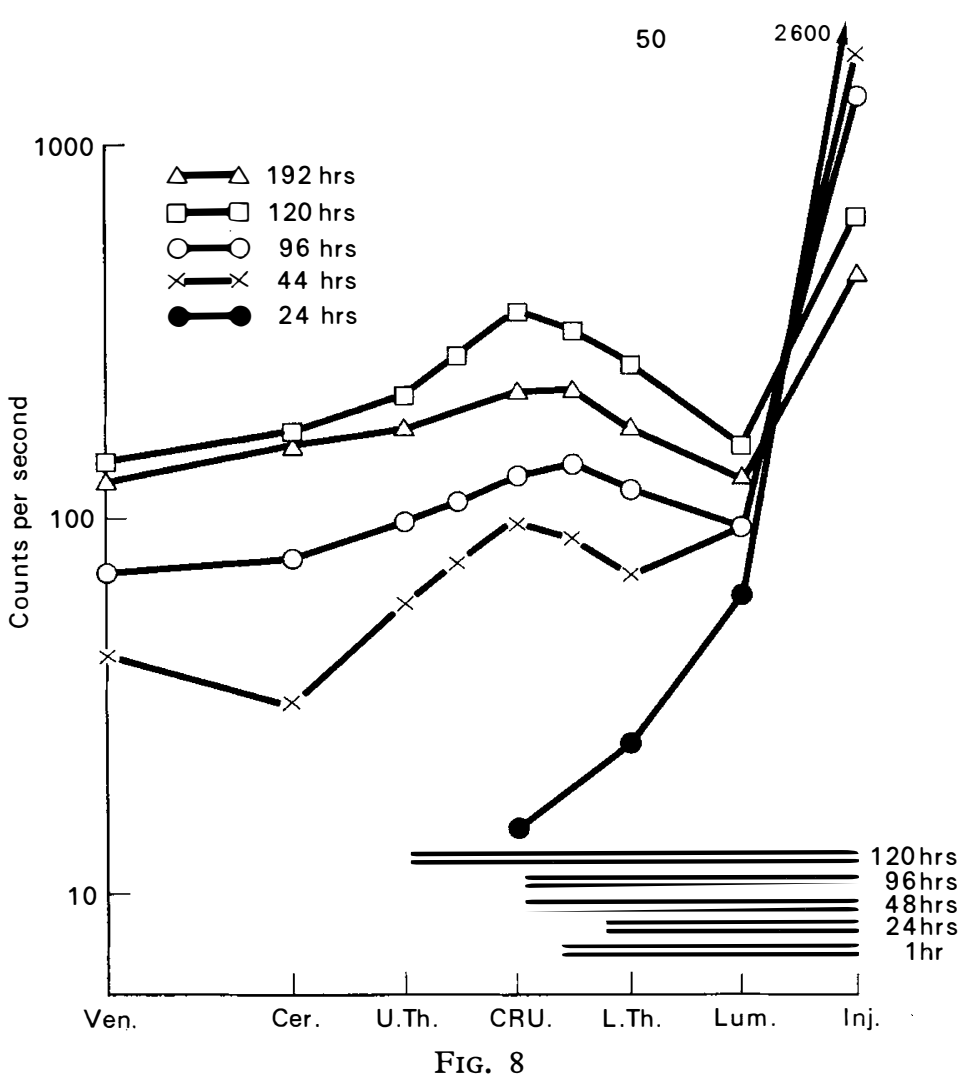

Results of contrast myelography, repeated at intervals after injury, compared with isotope myelography (I ${ }^{131}$ R.I.S.A.) using point counting along the vertebral column. A complete block is only present at 24 hours and becomes incomplete at 44 hours (isotope myelography). Pantopaque myelography suggests the complete block persists up till $\mathrm{I} 20$ hours after injury.

These results emphasise the limitations of contrast myelography in the assessment of the degree of spinal cord swelling within the theca. Because Pantopaque is 25 times more viscous than cerebrospinal fluid, a more accurate assessment of cerebrospinal fluid dynamics around a swollen segment of spinal cord will be made with isotope myelography using point counting (fig. 8).

In a series of 18 animals, a complete block within two hours of the contusion was demonstrated by both contrast and isotope myelography in only four animals. The variation in the degree of block produced by the controlled crush injury was evident from the fact that I4 animals out of the total group (I8) showed varying degrees of spinal cord swelling, resulting in incomplete blocks to cerebrospinal fluid flow. These results emphasise the variation in the response of spinal cord tissue to injury under controlled experimental conditions.

Clinical Recovery in the Control and Treated Animals. The composite chart from 72 clinical examinations of 15 control animais demonstrated a mean recovery (both sensory and motor) after three months of 50 per cent. The composite chart from 62 clinical examinations of I I sheep, which received methyl 


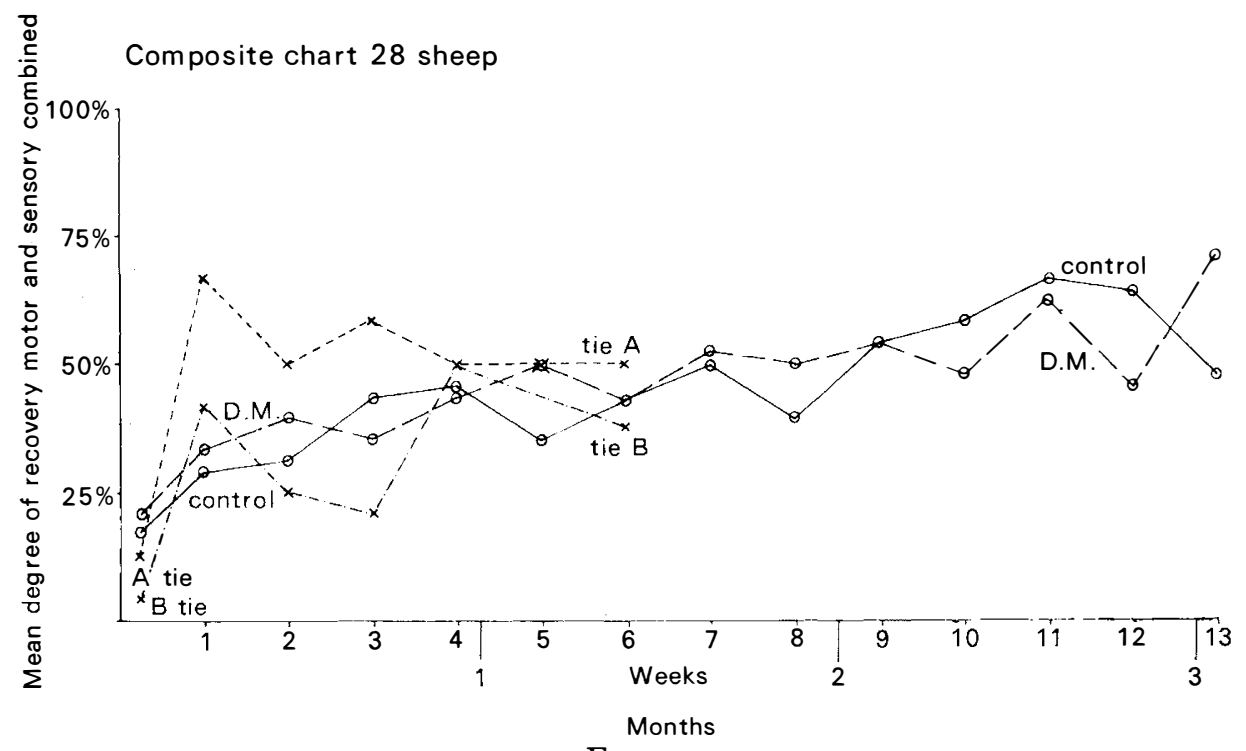

FIG. 9

Graph: Compares the mean percentage of motor and sensory recovery in treated (DM $=$ methyl prednisolone) and untreated (control) paraplegic animals over I3 weeks. Motor and sensory recovery in 'TIE A' and 'TIE B' animals (2) was recorded for six weeks, after the spinal cord at Tio level was constricted for 48 hours with a firm tape.

prednisolone ('Depo-Medrol'), showed a pattern of recovery after three months of 60 per cent. This apparent improvement was not statistically significant.

The mean clinical recovery (both motor and sensory combined) of both the control and treated animals was compared to the recovery in two animals in which the spinal cord was firmly constricted with a tape for 48 hours. The complete block to cerebrospinal fluid flow was confirmed during this period, when the spinal cord would have suffered significant ischemia. There was a similar trend in the pattern of motor and sensory recovery in these two animals over six weeks, suggesting that ischemia and hypoxia could contribute significantly to the pathogenesis of post traumatic paraplegia (fig. 9).

In a second series of nine animals, four received alpha-methyl paratyrosine (100 mg./kg.) within 75 minutes of the injury and five animals received only an intravenous infusion of saline $(25 \mathrm{ml}$. $/ \mathrm{kg}$.). Clinical examination of these sheep over three months showed a significant improvement in motor power in the treated group compared to the controls. During the three month period of study, the mean motor recovery in the saline control animals never exceeded 45 per cent of normal power. At six weeks the motor power of the treated animals averaged 72 per cent and remained between 60-70 per cent for the remaining period of the study. There was no significant difference in the degree of sensory recovery in the treated group. Both groups showed a mean sensory recovery of 80 per cent of normal by six weeks. During the remaining period of the study, the average recovery varied between $70-85$ per cent in both groups. The composite recovery in the treated group at six weeks and 13 weeks was 85 per cent and 70 per cent of normal, compared to 60 per cent and 65 per cent in the control group (figs. IO, A, B, C). 


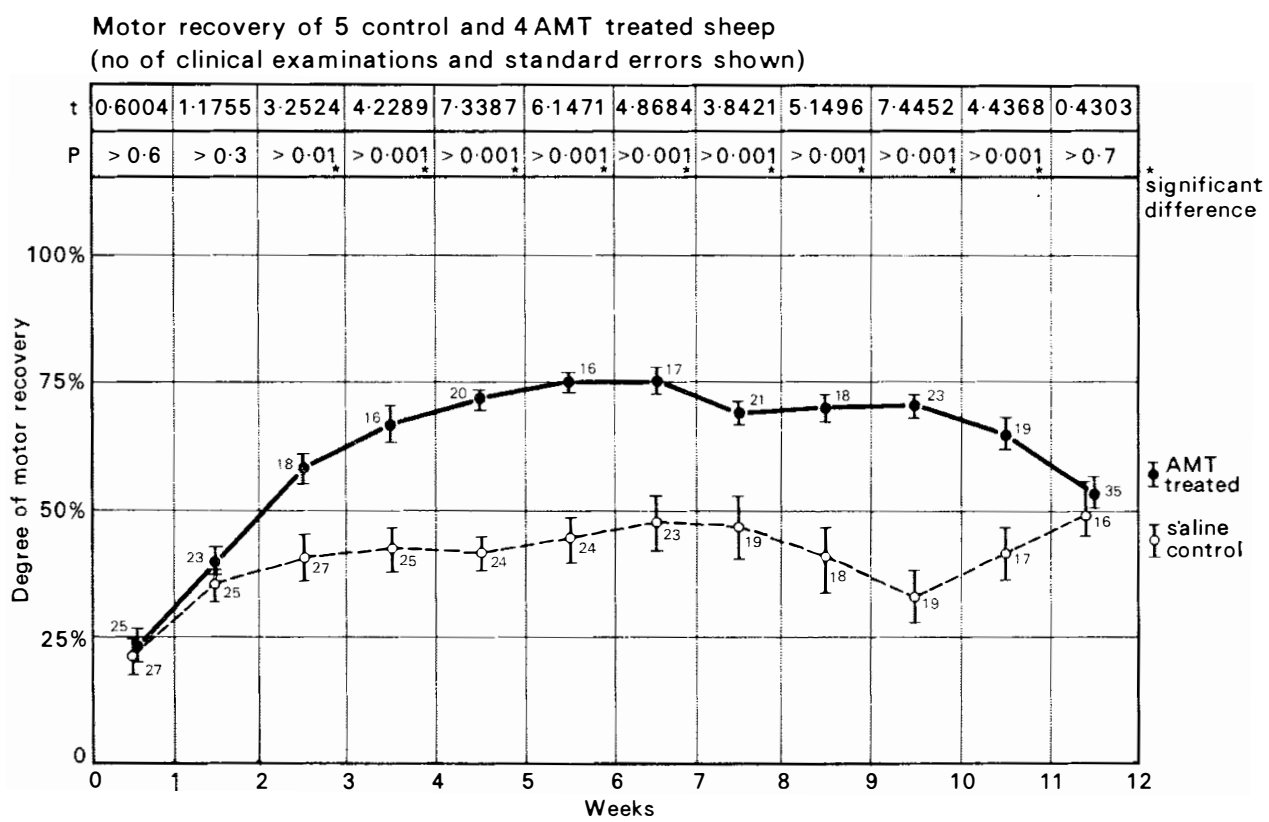

FIG. IO A

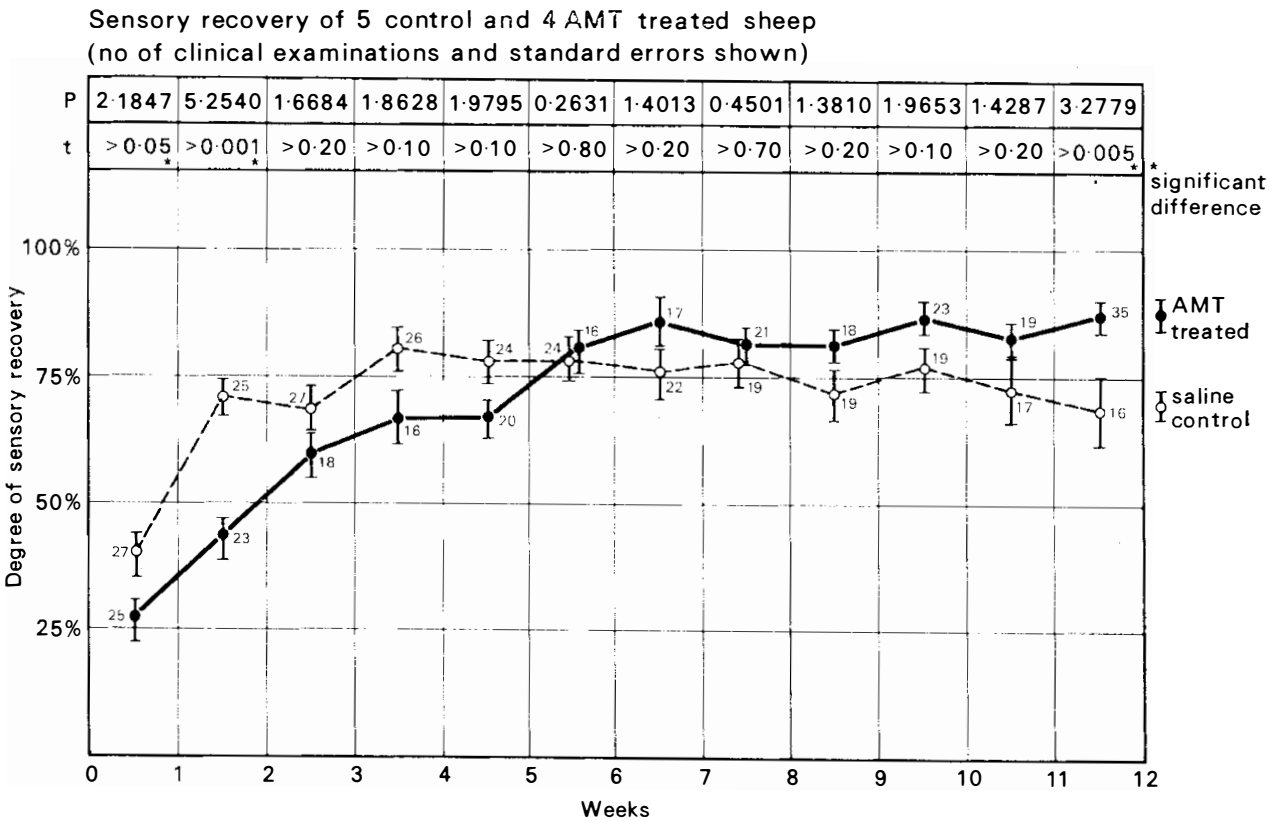

FIG. IO B 


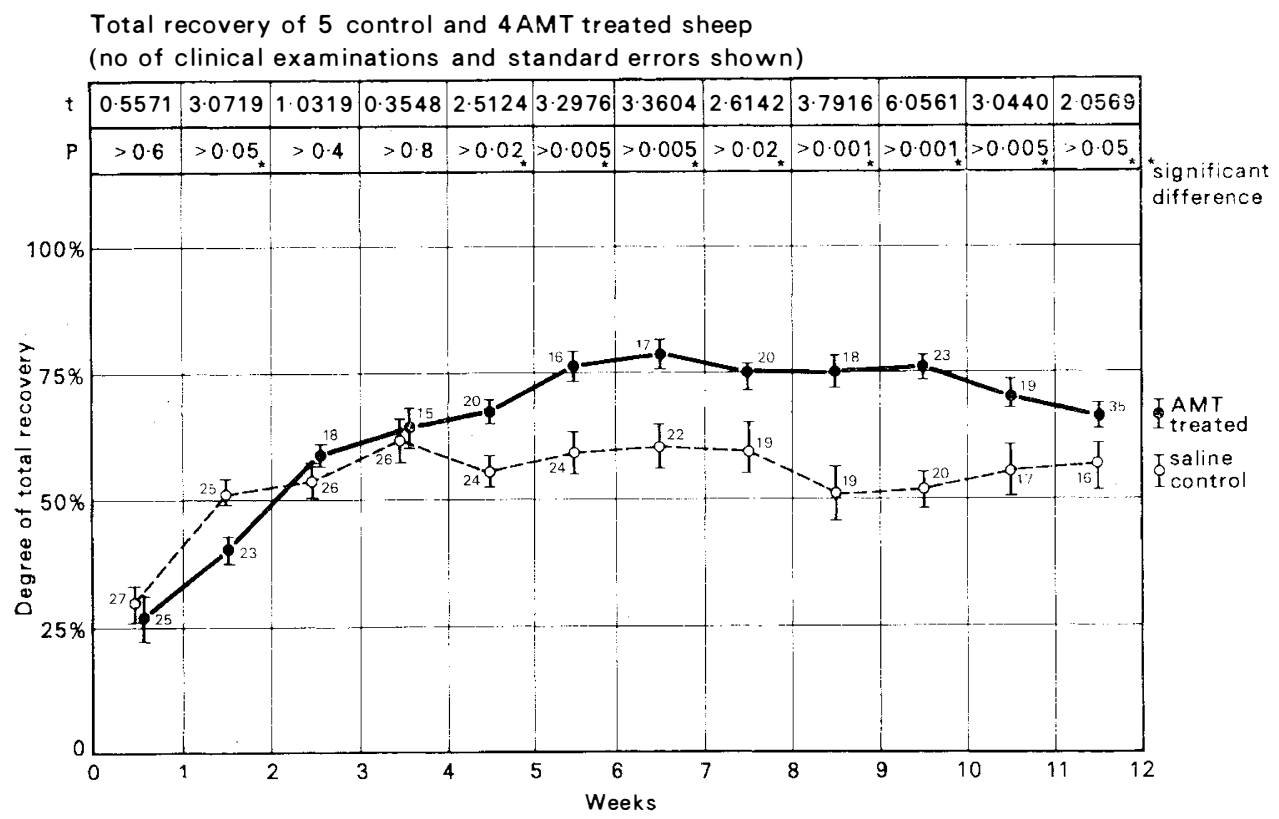

FIG. IO C

Mean percentage recovery in motor power and sensation in four treated animals (Alphamethyl paratyrosine) and five untreated (saline) animals, over 13 weeks. (A) Mean motor recovery (see left). (B) Mean sensory recovery (see left). (C) Combined mean sensory and motor recovery. Vertical bars indicate standard errors.

In four animals the ester form of A.M.T. was used (I00-I60 mg./kg.) to overcome the difficulties of dissolving A.M.T. in the powder form. All four animals died within three days. Autopsy did not reveal the cause of death. The animals, which had received treatment with A.M.T. (both salt and ester), had a massive diuresis following administration of the drug. In two of these animals there was a 45 times increase in the rate of urine output measured in the first hour after commencing the drug. The diuresis usually continued over a period of 48 hours. Intravenous therapy maintained adequate fluid intake in the animals during this period and there were no significant changes in the serum electrolytes. The histopathology in the spinal cords of these animals showed no significant difference from the control series.

Chronic Pathology Following Cord Contusion. At intervals between I and 13 weeks, the development of central cystic necrosis, gliosis and fibrosis was studied at the crushed Tro level. Eighteen animals were studied in this series and the central cystic necrosis which developed in many of these animals is demonstrated dramatically by dark field illumination. The spinal cord was sectioned in these animals at the level of the lesion and I $\mathrm{cm}$. above and $\mathrm{I} \mathrm{cm}$. below. Haematoxylin/ eosin and Luxol fast blue were used to identify the inflammatory reaction, congestion and extravasation of red blood cells, damage to anterior horn cells, disruption of myelin sheaths and swelling of the periaxonal spaces, swelling of the axon cylinders, glial cells and fibrosis. 


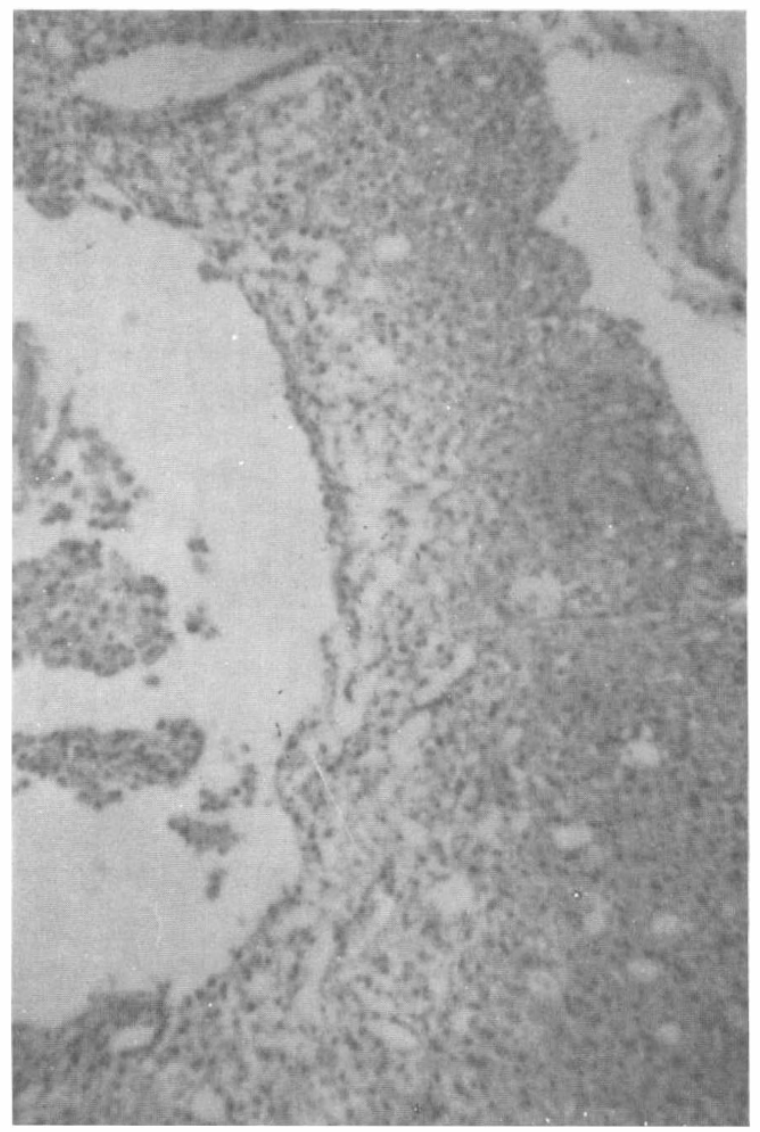

Fig. II A

I2 weeks: (Luxol fast blue stain). Central cystic degeneration with marked glial reaction at the level of the injury in untreated (control) animals. (A) Sheep $40(\times 50)$.

Small central cystic necrotic areas were demonstrated as early as one week after injury. These areas of necrosis were large in the specimens from animals which survived for longer periods. By two weeks, definite cysts within the central areas of the cord were identified and by four weeks there was further evidence of associated gliosis. This organisation of damaged tissue progressed until I 2 weeks, when there was either a serious deficit of neural tissue in the central part of the cord with only a small rim of myelinated nerve fibres or a mass of glial and fibrous tissue replacing most of the grey and white matter (figs. I I, A and B).

Two animals were studied over a period of six weeks. Both these animals had a firm tape tied around the spinal cord for 48 hours resulting in paraplegia. The clinical recovery of these animals was recorded. Despite significant loss of normal nerve tissue at the level of the lesion, both these animals made a similar recovery to the animals with a contusion injury. The degree of cystic degeneration. gliosis and fibrosis is similar to the pathology seen in the control series of animals. Considerable organisation by glial and fibrous tissue was apparent. 


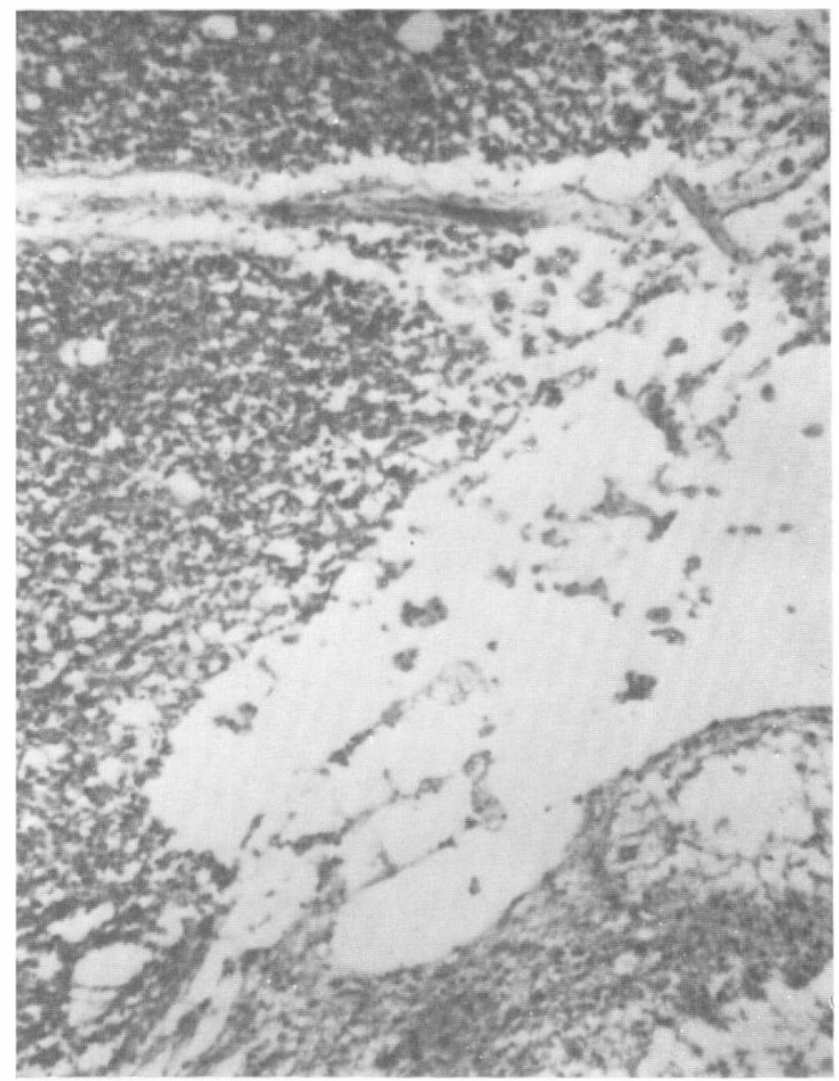

FIG. I I B

Sheep 4I $(\times 50)$.

In a series of II animals which received $40 \mathrm{mg}$. of methyl prednisolone (Depo-Medrol) intrathecally one hour after injury, pathology was studied at intervals between one week and I 3 weeks. No significant change in the extent or degree of cystic degeneration in the spinal cords of the treated animals was seen when compared with the controls. Associated gliosis and fibrosis appeared after six weeks and was well established by 13 weeks. The pathological findings are consistent with the clinical assessment of motor and sensory recovery in these animals (figs. I2, A and B).

In a series of nine animals which received alpha-methyl paratyrosine (I00 mg./kg.), the pathology was studied at intervals between two days and I3 weeks. There appeared to be a comparable degree of congestion and extravasation within two days of the injury. This was associated with a breakdown of the myelin sheaths to form microcysts. Central cystic necrosis occurred by the second week with active gliosis evident at three weeks. By 13 weeks there was a significant loss of myelinated nerve tissue with extensive gliosis and fibrosis. Also there appeared to be less central cystic change in the spinal cords of these animals (fig. 13). The pathological findings do not appear to explain the clinical improvement in motor 

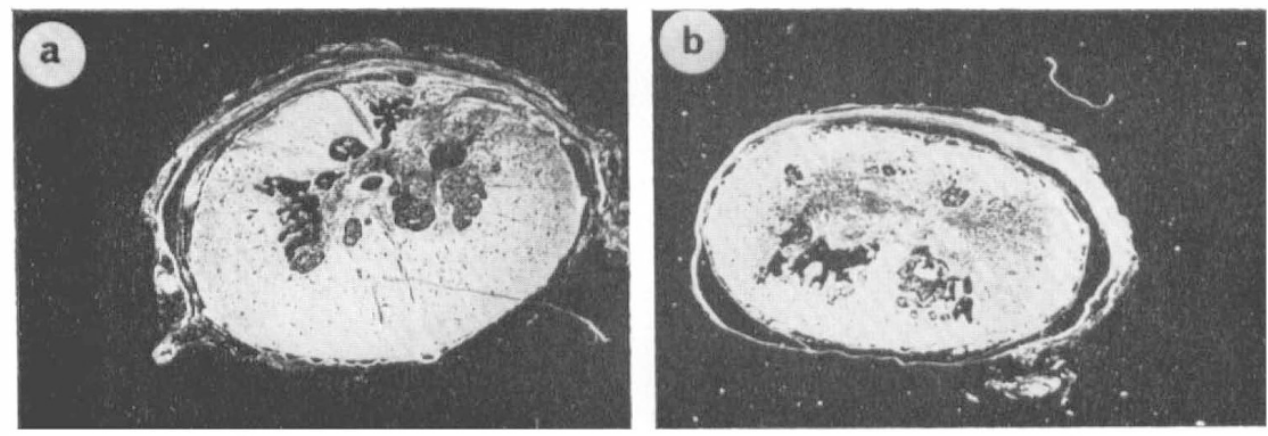

FIG. I2 (A) and (B)

(A) Sheep 50. Central cystic degeneration in untreated (control) animal ro weeks after injury. (B) Sheep 5I. Central cystic degeneration in a treated (methyl-prednisolone) animal to weeks after injury.

power seen in this group of animals. Sections of both kidneys and liver were taken at autopsy in all animals, but no significant pathology attributable to the drug therapy was found. Most of the animals studied had evidence of mild pyelonephritis.

\section{DISCUSSION}

The evidence, which is now rapidly accumulating, suggests that the apparently irreversible changes in the spinal cord following contusion injury may be partially reversed by physical or chemical means. By various surgical and non-surgical techniques in the experimental animal (e.g. local saline perfusion, steroids, myelotomy, monoamine inhibition and hyperbaric oxygen therapy) it has been possible to modify what would otherwise be permanent paraplegia. There are conflicting reports on the pathogenesis of these progressive changes in the microvasculature and nerve fibres of the spinal cord. Fluorescent microscopy (Wagner, Green and Bucy, I97I) has demonstrated the time related formation of extravasation and oedema within the central grey matter. However, serial injections of fluorochrome stain, which binds to the endothelium have shown that there is marked reduction in perfusion of the central grey matter within eight hours (Dohrmann, Wick and Bucy, 1973).

We have not been able to demonstrate the widespread oedema which is reported by other workers. Swelling of the spinal cord, which occurs within minutes of the injury, appeared to be due to the intracellular swelling of the axons with increased periaxonal spaces, congestion and extravasation. There is little evidence in the paraplegic sheep of an increase in the intercellular space in the region of the spinal cord within four hours. Only in the contused spinal cord from perfused sheep was there any evidence of oedema. In these animals, myelinated nerve fibres appeared 'constricted' within the fluid-bound areas of white matter. The technique of perfusion fixation required intravascular pressures up to $160 \mathrm{~mm}$. $\mathrm{Hg}$. and presumably this technique produced a significant amount of transudate fluid in the intercellular spaces.

The absence of significant, extracellular oedema fluid has been emphasised by other 


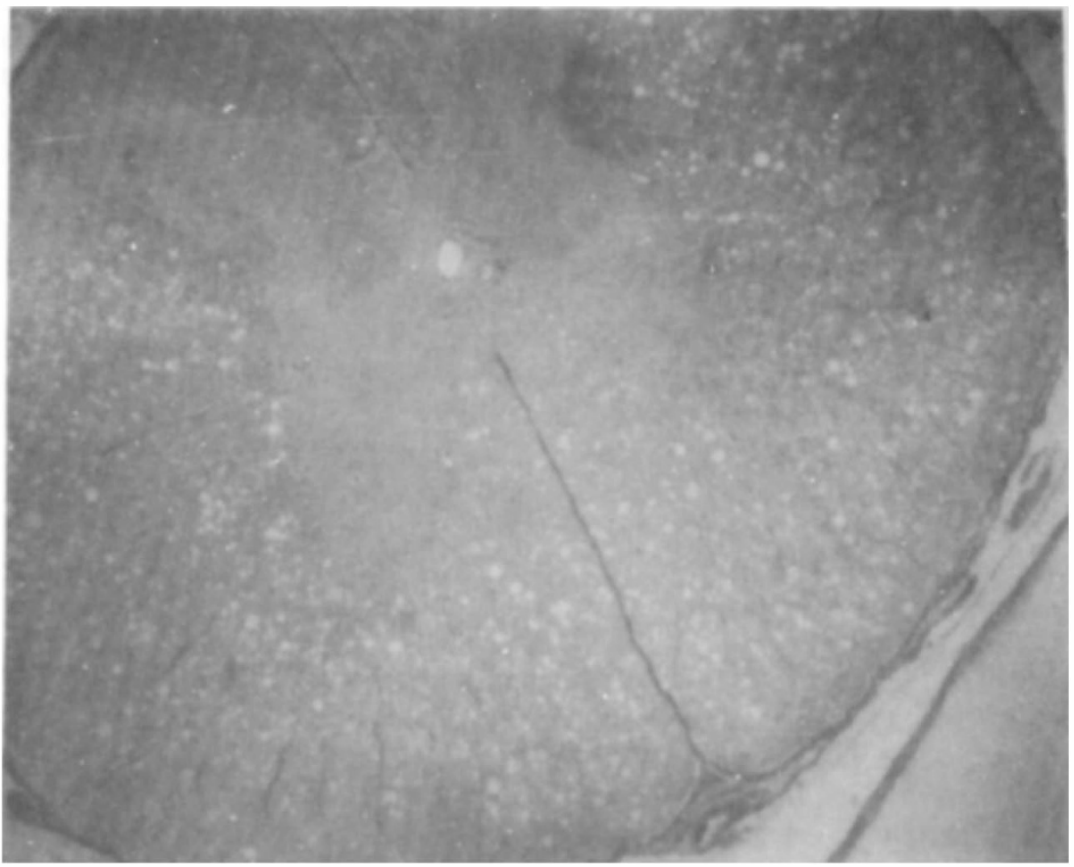

FIG. I3

Numerous microcysts in the white matter of the spinal cord of a treated animal (No. I20alpha methyl-paratyrosine), I3 weeks after the contusion injury. There is less gross central cystic degeneration.

workers (Vise et al., I974) and suggests some variation in the cellular and humoral response to tissue damage in the spinal central nervous system.

The reported fourfold increase in the levels of noradrenaline (NA) and the low levels of dopamine (DA) within one hour (Osterholm and Mathews, I972) have not been substantiated in more recent work by other laboratories. There is some further evidence that dopamine, rather than diminishing in amount, may rise in local concentration (Naftchi, Demeny, DeCrescito, Tomasula, Flamm and Campbell, 1974). Obviously the time interval following the trauma is important and further work on monoamine 'turnover' is necessary to elucidate this complex problem.

The difficulties in obtaining a constant pathological lesion from a controlled contusion injury in the experimental animal has been emphasised by this study. There was a variation in the motor response following the applied electrical stimulus to the exposed spinal cord immediately after injury.

Isotope myelography indicated that within two hours of the injury, a wide variation in the amount of cord swelling occurred with different sheep. Within four hours of injury there was also a wide variation in the degree of paraplegia (0-58 per cent of normal motor power). These findings emphasise how difficult it is to achieve a reproducible degree of contusion.

It is possible that following direct injury, physical and biochemical mechanisms 
contribute to further necrosis of neural tissue by progressive ischemia and hypoxia (Kelly, Lassiter, Calogero and Alexander, 1970). The sequential pathological changes described in the moderately contused spinal cord of the sheep support many of the reports from experimental work carried out in other animals. The earliest pathological changes in neurones are evident within 15-30 minutes. Intramedullary congestion and extravasation of blood, initially in the grey and later in the white matter, are evident at IO-I 5 minutes. This evidence suggests that a local sluggish circulation in an already compromised area of nervous tissue may well lead ultimately to irreversible neural degeneration.

Reversible paraplegia has been proven in the experimental animal, but is yet to be demonstrated convincingly in man. In Spinal Injuries Units, the initial major problem for the clinician is the difficulty in differentiating concussion, contusion, and laceration of the spinal cord. Spinal shock has a damping effect on neuronal function at and below the level of the spinal lesion. There is a limited armamentarium of clinical tests available to help differentiate the pathology present within four hours of injury. The findings of lumbar puncture are of little diagnostic significance. Contrast myelography exposes the recently injured patient to a painful and hazardous manipulation. This investigation may provide misleading evidence of a 'complete' spinal fluid block as contrast medium such as 'Pantopaque' has a viscosity that is 25 times heavier than cerebrospinal fluid. Isotope myelography in this laboratory has proved to be a more reliable means of elucidating the degree and extent of spinal fluid block and by inference, the degree of cord swelling. Within two hours after injury the degree of spinal cord swelling varied with the same injury in different animals. Isotope myelography demonstrated that even a tensely swollen cord rapidly reduces in size over 48 hours. Pantopaque myelography could suggest that the spinal cord remained tightly swollen and ischemic within the theca for a longer period. Isotope myelography with a simple portable counter can now be used to assess the degree and extent of spinal fluid block in the recently injured spinal patient.

No significant difference in clinical recovery was evident in the animals treated with steroids. Other workers have reported improved recovery in animals following treatment with intramuscular steroids (Ducker and Hamit, 1969). The 'depot' form of methyl prednisolone (Depo-Medrol) allows only a slow release of the steroid four hours after the injection. Therefore significant local levels of the drug may not have accumulated until after irreversible pathology had occurred.

In these studies there was a significant improvement in the motor recovery in animals treated with alpha-methyl paratyrosine. After three months no significant difference in the histopathology of the cord lesions in the animals treated with methyl prednisolone was seen when compared with the pathology in the spinal cords of the control group. There appeared to be less central cystic change in the spinal cords of those animals treated with A.M.T.

This finding may explain the reason why there appeared to be a significant motor recovery in those animals treated with A.M.T. Variation in the dosage and rate of administration of A.M.T. will be further studied. In our series, all the animals receiving A.M.T. had an impressive diuresis requiring careful intravenous management and replacement of fluid within the following 48 hours. Within the first hour the urine output increased significantly in the treated animals. This effect of A.M.T. has not been previously reported and possibly some of the beneficial effects of the drug may be related to this influence on renal function. In this study there has been no evidence of 
renal damage in either the short or long term animals. In both the treated and untreated animals, there has been clinical recovery of both motor power and sensation below the level of the lesion, despite a significant loss of neural tissue in the spinal cord.

\section{SUMMARY}

The validity of reproduction of the controlled contusion injury to the spinal cord in the experimetal animal is questioned. The dynamic pathology involving the microvasculature within the first two hours is illustrated using light microscopy. After I 5-30 minutes swelling of axons and disruption of myelin sheaths become evident in most areas of white matter. After four hours microcysts have formed in the columns of white matter and are evidence of irreversible damage.

Swelling of the cord following injury results from congestion, extravasation and intracellular swelling of neurones, rather than from any demonstrable increase in extracellular fluid. Oedema was only demonstrated with perfusion fixation. Isotope and contrast myelography were compared in the identification of the degree and extent of spinal cord swelling.

Significant improvement in motor power was found in a group of paraplegic sheep treated with alpha-methyl paratyrosine. There was no significant improvement in the degree of recovery of motor power or sensation in those animals treated with intrathecal methyl prednisolone (Depo-Medrol). The histopathology in the crushed spinal cord tissue of the treated and untreated animals at various intervals of time was compared. Some possible explanations for the different patterns of clinical recovery in the treated animals are discussed.

Acknowledgements. The authors are grateful for the interest and encouragement in this project by Professor T. Reeve, Department of Surgery, Royal North Shore Hospital of Sydney. The significant contributions to the project by Messrs. R. Sherwood, R. Kearns, W. Brown and R. Israel, Technical Assistants, Mrs. D. Clancy, secretary to the Spinal Injuries Unit, are acknowledged.

This research project has been supported by grants from the National Health and Medical Research Council, the Spinal Injuries Research Fund, The Surgical Research Fund, Royal North Shore Hospital of Sydney, Upjohn Pharmaceutical Company and the Paraplegic and Quadriplegic Association of New South Wales.

\section{REFERENCES}

Albin, M. S., White, R. J., Acosta-Rua, G. \& Yashon, D. (I968). Study of functional recovery produced by delayed localised looking after spinal cord injury on primates. F. Neurosurg. 29, I I3-I20.

DohrmanN, G. J., WICK, K. M. \& BuCY, P. C. (I973). Spinal cord blood flow in experimental traumatic paraplegia. $\mathcal{F}$. Neurosurg. 38, 52-58.

Ducker, T. B. \& HAMIT, H. F. (1969). Experimental treatments of acute spinal cord injury. F. Neurosurg. 30, 693-697.

Kelly, D. L., Lassiter, K. R. L., Calogero, J. A. \& Alexander, E. (1970). Effects of local hypothermia and tissue oxygen studies in experimental paraplegia. $\mathcal{F}$. Neurosurg. 33, 554-563.

Naftchi, N. E., Demeny, M., DeCrescito, V., Tomasula, J. J., Flamm, E. S. \& Campbell, J. B. (I974). Biogenic amine concentrations in traumatized spinal cords of catseffect of drug therapy. F. Neurosurg. 40, 52-57.

Osterholm, J. L. \& MATHEws, G. J. (1972). Altered norepinephrine metabolism following experimental spinal cord injury. Part $\mathrm{I}$ : Relationship to hemorrhagic necrosis and post-wounding neurological deficits. F. Neurosurg. 36, 386-394. 
VISE, W. M., YASHON, D. \& HUNT, W. E. (I974). Mechanisms of norepinephrine accumulation within sites of spinal cord injury. $\mathcal{F}$. Neurosurg. 40, 76-82.

WAGNER, F. C., GREEN, G. A. \& BUCY, P. C. (I97I). Spinal cord edema associated with paraplegia. Proc. I8th Veterans Administration Spinal Cord Injury Conference, pp. 9-IO.

Yeo, J. D., PAYNe, W. \& Collins, L. T. (I97I). Controlled experimental contusion of the spinal cord of sheep. Proc. Surgical Research Soc. of Australasia, Scientific Meeting. Aust. E N.Z. F. Surg. 4I, No. I, 89-90.

\section{Discussion}

Dr. F. W. MeINECKe (Germany). I would like to thank my friend John Yeo very much for his excellent paper, and ask a question. How would you explain the increase of an incomplete lesion as a result of oedema with the results you had in your experiments?

Mr. P. HARris (G.B.). I also enjoyed Dr. Yeo's paper. I would like to ask a couple of questions. What is the length of period of spinal shock in the sheep that he uses? Secondly, in the experimental study of trauma in animals, how akin is this to the situation in man? We are dealing with a different type of injury altogether. Has he tried to simulate the situation in man? I think this is lacking in many, if not most, of the experimental studies which involve animals, so that it would be quite difficult to relate this, I think, to the human situation.

And thirdly, I am not certain, although I should know this from his previous work, if the dura is opened or not, because these animals do then start off with a decompressive laminectomy, of which, of course, I personally do not approve. Does this play any part in the situation?

Prof. M. Weiss (Poland). I also very much admire these experiments made in relation to the clinical symptoms by Dr. Yeo. This is a beautiful model for studying different techniques of treatment. Not to compare, of course, to the human situation, but as I feel he clarified much concerning the effects of steroids and other drugs, I would like to ask him if he tried local cooling, which probably can be a factor for terminating or diminishing local swelling.

Dr. Masalawala (India). I think this paper needs to clarify the difference between a compression fracture and a fracture dislocation as occurs in the human being. A very small experiment was carried out in our Unit on cervical dislocation and fractures on patients who died sometimes after 48 hours, sometimes after three days, etc., etc. They showed that the damage in the cord was not exactly locally at the site of the injury but spread up and down in a sort of spindle shape, the maximal degree of damage being opposite the fracture but extending for two inches almost coming to a pinpoint above and below, which accounts for the bizarre clinical picture. Any model, such as Dr. Yeo has shown, does not include the factor of rotation and stress on the spinal cord as a whole, and therefore does not really compare with the injuries in a human being. But I have no doubt it will be useful for judging the effects of certain drugs merely in relieving swelling.

Another point I would also like to make is that the dura is a fairly strong membrane, and any swelling of the cord coming within must cause a certain amount of compression.

SIR LUDWIG GuTtMANN (Chairman). If there are no more questions or comments, I would like to make a few comments. I think what Masalawala has just said is very apt. All these experimental studies, however detailed they are, do not give a clear picture of what happens in human injuries. The factor of rotation in most of the fracture dislocations is, I think, the main cause of the widespread damage to the spinal cord. This, as I have pointed out before, is due to a stretching and squeezing effect on the spinal cord above and below the level of the lesion. Whether you have an antero-hyperflexion or a retroflexion injury (the latter called commonly hyperextension injury), the cord at the level of the injury is fixed. But above and below, whatever the injury might be, you may get a stretching (distraction) of the spinal cord by the movement of the body, and/or the head 